\title{
Design Goals and Status of the WENDELSTEIN 7-X Project
}

\author{
M.Wanner and the W7-X Team \\ Max-Planck-Institut für Plasmaphysik, EURATOM-Association \\ Teilinstitut Greifswald, D-17489 Greifswald, Germany
}

\section{Introduction}

The stellarator experiment WENDELSTEIN 7-X (W7-X) follows the successful experiment WENDELSTEIN 7-AS and is one of the largest fusion experiments under construction. W7-X is part of the European Fusion Programme and aims to explore and demonstrate the reactor potential of the stellarator principle.

The total investment costs of about 300 million EURO are carried jointly by the European Commission, the Federal Government of Germany and the State of Mecklenburg-Vorpommern. The investments cover the build-up of a new branch of IPP in Greifswald, the construction of the stellarator with a major radius of $5.5 \mathrm{~m}$, the installation of $10 \mathrm{MW}$ ECR, 4 MW ICR and 5 MW NBI heating and the necessary infrastructure. From 2004 on a staff of about 300 employees including 90 scientists will work in the Greifswald branch of IPP.

In contrast to tokamaks stellarators are characterised by the absence of a net toroidal current. This allows stellarators to operate by principle in steady state which makes them especially attractive as a power reactor.

The design of $\mathrm{W} 7-\mathrm{X}$ is determined by the physics goals of the experiment and considers engineering aspects of a future power reactor e.g. the use of superconducting coils, a modular design of the magnet system and steady state operation of all components. W7-X does not aim, however, to study a burning plasma and hence will not use Tritium.

\section{Technical requirements}

The magnetic configuration of W7-X is of the HELIAS type and is characterised by a helical plasma column with a cross section which varies periodically between a bean shape and a triangular shape. To provide the necessary twist of the magnetic field lines a poloidal magnetic field is superimposed on the main toroidal field. This magnetic field geometry is defined by an idealised distribution of currents outside the plasma. The shape of the magnetic cage is accordingly optimised to achieve good particle confinement and MHD stability and to make sure that the position and boundary of the plasma remain stable for a wide range of densities and temperatures. In addition the magnetic configuration keeps the bootstrap current small, brings the neoclassic transport close to that of tokamaks and captures fast He-particles to explore their confinement in a later HELIAS power plant. /1,2,3/

The modular design of the coil system is required to allow for assembly and maintenance of the power reactor. The evenly distributed currents which result from the optimisation of the magnetic field are therefore segmented into 50 current lines. These current lines are used to define the shape of the finite sized winding packages of the coils. From the field geometry it follows that five differently shaped coils with non-planar windings are required for each half 
module. This arrangement allows to assemble and remove individual modules radially and reduces the magnetic ripple to an acceptable level.

The shape of the individual coils has to obey the finite bending radius of the conductor as well as the need for space for structural support and sufficient clearance for access to the plasma.

The magnetic cage of a HELIAS type power reactor is characterised by an iota close to one and small shear and will be based on 50 non-planar coils only. For the purpose of experimental flexibility W7-X will be able to vary the iota between $4 / 5$ and $6 / 5$ by using 20 auxiliary planar coils superimposed on the non-planar coils.

In order to reach the predicted performance of the magnetic configuration, the dimensions of the individual coils as well as their position must be within tolerances of a few thousands of their nominal values.

Steady state operation of the magnet system at an induction of $3 \mathrm{~T}$ can only be achieved economically by the use of superconducting coils. The low operation temperature of the magnet coils of about $4 \mathrm{~K}$ is provided by a helium refrigeration system and requires a very effective thermal insulation. For that reason the coils are housed in a cryostat. The heat flow to the cryogenic components is minimised by radiation shields, which are cooled to about $80 \mathrm{~K}$, vacuum and superinsulation.

About 300 access ports are provided to heat and study the plasma, to pump off neutralised particles and to supply the plasma facing components with coolant. Fig. 1 shows a CAD-view of the W7-X stellarator.

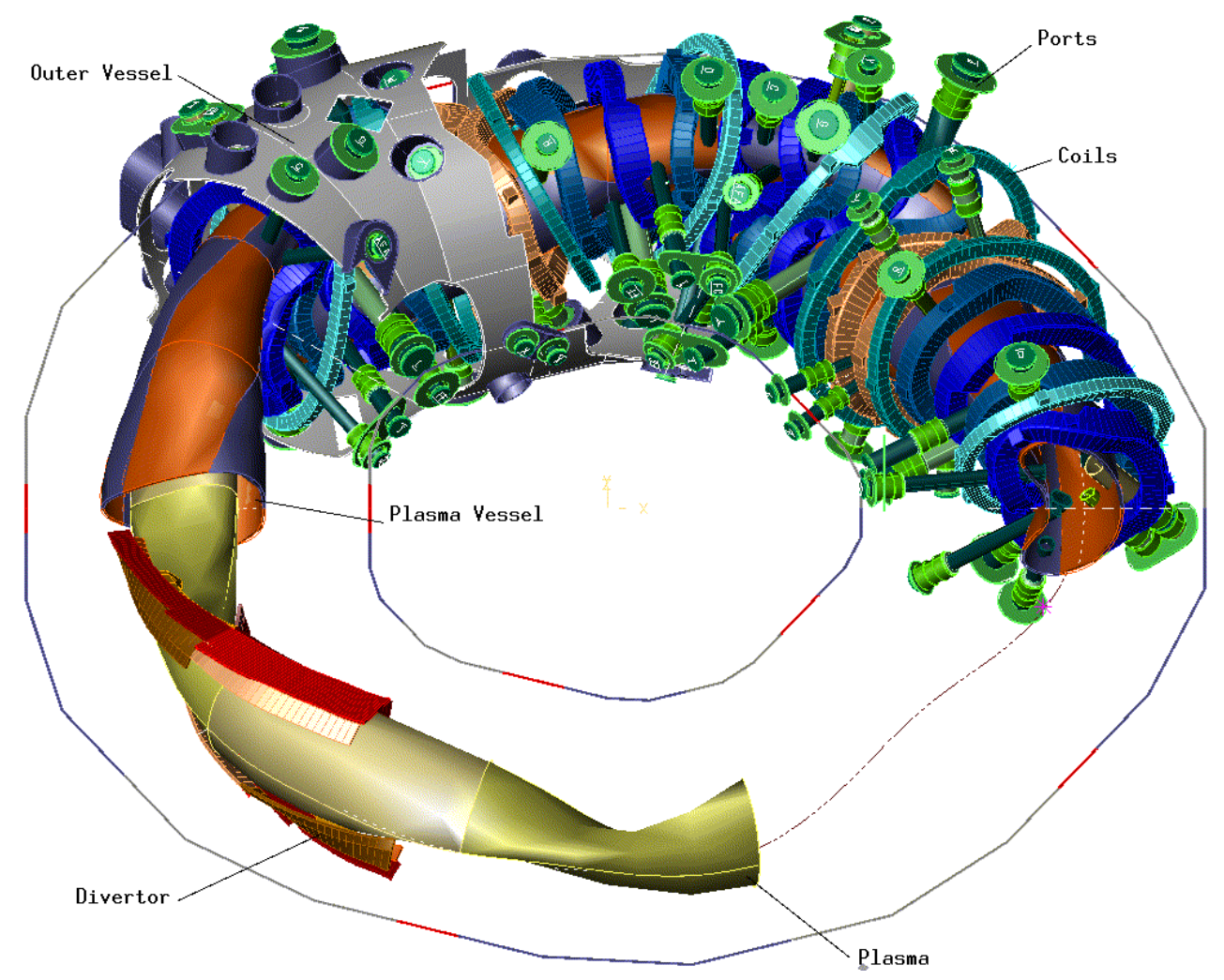

Fig. 1: View of the W7-X stellarator showing the plasma, the divertor elements, the plasma vessel, the coil system, the outer vessel and access ports. 
The inner vessel of the cryostat encloses the plasma and follows its helical shape. To control the flow of hot particles from the plasma W7-X is equipped with an open divertor. Particles which have passed the last closed magnetic surface will follow the open field lines in the magnetic islands and are focused on the target plates where they are neutralised and pumped off. Ten assemblies of target plates covered with graphite are placed symmetrically along the edge of the plasma column and have to withstand a steady state thermal load of up to $10 \mathrm{MW} / \mathrm{m}^{2}$. The investigation of the interactions of the energy and particles with the target plates as well as the retention of neutral impurities from reentering the plasma are essential objectives of the scientific programme of W7-X.

W7-X shall already demonstrate that the components used can be scaled up for a future power reactor. Complementary work is therefore performed to study the design of a HELIAS type power reactor. /4/ The major technical parameters of WENDELSTEIN 7-X are compared with those of a potential HELIAS reactor in table 1.

\begin{tabular}{|l|l|l|}
\hline & WENDELSTEIN 7-X & HELIAS reactor \\
\hline Total diameter of the machine & $15 \mathrm{~m}$ & $55 \mathrm{~m}$ \\
Height of the machine & $4 \mathrm{~m}$ & $15 \mathrm{~m}$ \\
Total weight of the machine & approx. 700 t & approx. 40.000 t \\
Major plasma radius & $5.5 \mathrm{~m}$ & $22 \mathrm{~m}$ \\
Average minor plasma radius & $0.53 \mathrm{~m}$ & $1.8 \mathrm{~m}$ \\
Plasma volume & $30 \mathrm{~m}^{3}$ & $1400 \mathrm{~m}^{3}$ \\
Plasma mass & $0.005-0.03 \mathrm{~g}$ & $0.2-1 \mathrm{~g}$ \\
Number of non-planar coils & 50 & 50 \\
Magnetic induction on axis & $3.0 \mathrm{~T}$ & $4.8 \mathrm{~T}$ \\
Maximum induction at the conductor & $6.7 \mathrm{~T}$ & $10 \mathrm{~T}$ \\
Energy stored in the magnet system & $0.6 \mathrm{GJ}$ & $100 \mathrm{GJ}$ \\
ECR-heating for start-up & $10 \mathrm{MW}$ & $50-100 \mathrm{MW}$ \\
Fusion power (thermal) & - & $3600 \mathrm{MW}$ \\
\hline
\end{tabular}

Table 1: Comparison of the technical data of WENDELSTEIN 7-X and a HELIAS-reactor.

Heating of the plasma of W7-X will be achieved by different technologies. A total heating power of $15 \mathrm{MW}$ will be provided in a first stage to heat the electrons to $8 \mathrm{keV}$ and the ions to $3 \mathrm{keV}$.

ECR heating will be the basic method to start and heat the electrons of the plasma. The system is based on ten gyrotrons which operate at a frequency of $140 \mathrm{GHz}$ and with a power of $1 \mathrm{MW}$ each. Forschungszentrum Karlsruhe (FZK) develops the microwave sources in collaboration with Max-Planck-Institut für Plasmaphysik, Éole Polytechnique Fédéral de Lausanne and industry and will provide the complete ECRH system for W7-X together with Institut für Plasmaforschung Stuttgart.

Additional heating of the ions is achieved by a radiofrequency system with a maximum power of $4 \mathrm{MW}$. In order to increase density and temperature of the plasma a total heating power of $5 \mathrm{MW}$ using neutral beams of hydrogen with an energy of $55 \mathrm{keV}$ resp. deuterium with $65 \mathrm{keV}$ will be available. 
All components of W7-X are designed for steady state plasma operation. Plasma discharges will however be limited to a maximum of 30 minutes because of the capacity of the water cooling system.

\section{R\&D Activities}

To prove the design of the machine, the development of critical technologies started well in advance of the project. This holds for the development of the superconductor, the manufacture of a prototype of a superconducting coil and a sector of the cryostat, the development of target elements for the divertor and of powerful microwave sources for ECRH.

The conductor is based on NbTi and was developed in co-operation with FZK. To carry a current of $18 \mathrm{kA}$ the conductor uses 243 strands which are wound to a cable. The cabling avoids relative movement of the strands under the Lorentz forces. The cable is enclosed and reinforced by an Al-alloy jacket. The void fraction inside the Al-jacket amounts to $37 \%$ and is used as cooling channel for the liquid helium. The choice of the Al-alloy considered that the conductor must be soft enough to be wound to the desired shape and must be hardened after winding by a heat treatment to withstand the large forces in the machine. This concept of a cable-in-conduit conductor was developed and improved in several steps. Meanwhile samples of the conductor with a total length of more than one kilometre have been produced and tested. The conductor has meanwhile been approved for the production of $60 \mathrm{~km}$ of conductor necessary for W7-X. This design also considers the requirements of a HELIAS type reactor and can be adopted for its magnet coils. /5/

An essential requirement for the good confinement of the plasma is the precise shape and arrangement of the magnet coils. Therefore the dimensions of the winding package must not differ from their design value by more than a few millimetres. The winding package of each coil is divided into six double layers which are precisely pressed into a mould. The conductor has to be protected against voltages of up to $12 \mathrm{kV}$ which occur during a rapid shutdown of the magnetic field. The electric insulation of the conductor and the winding package is achieved by glassfiber tapes and epoxy.

The winding package needs additional reinforcement to withstand forces of up to $4 \mathrm{MN}$ and is therefore welded into a steel casing. The space between the winding package and the casing is filled with epoxy-impregnated glass sand and ensures a uniform transmission of the forces from the conductor to the casing. The double layers of the winding package are electrically connected in series. In order to minimise the dissipation of ohmic heat at cryogenic temperatures the resistance of the electric joints between the double layers has to be below $1 \mathrm{n} \Omega$.

The feasibility to produce the unconventionally shaped non-planar coils was demonstrated by a prototype coil manufactured by the companies Noell and Ansaldo. /6/ Meanwhile this prototype coil has successfully passed acceptance tests in the TOSKA facility of FZK (Fig. 2). After a test at the nominal current of $18 \mathrm{kA}$ the coil was operated in the $6 \mathrm{~T}$ background field of the magnet coil of the former Large Coil Task programme up to $114 \%$ of its nominal mechanical load. Deformations stayed in the elastic range as predicted. Quenches which were induced on purpose started from the high field layer as expected. The critical currents 
corresponded to the measurements taken at the virgin strands. With these positive results the manufacture of the coil system could be released.

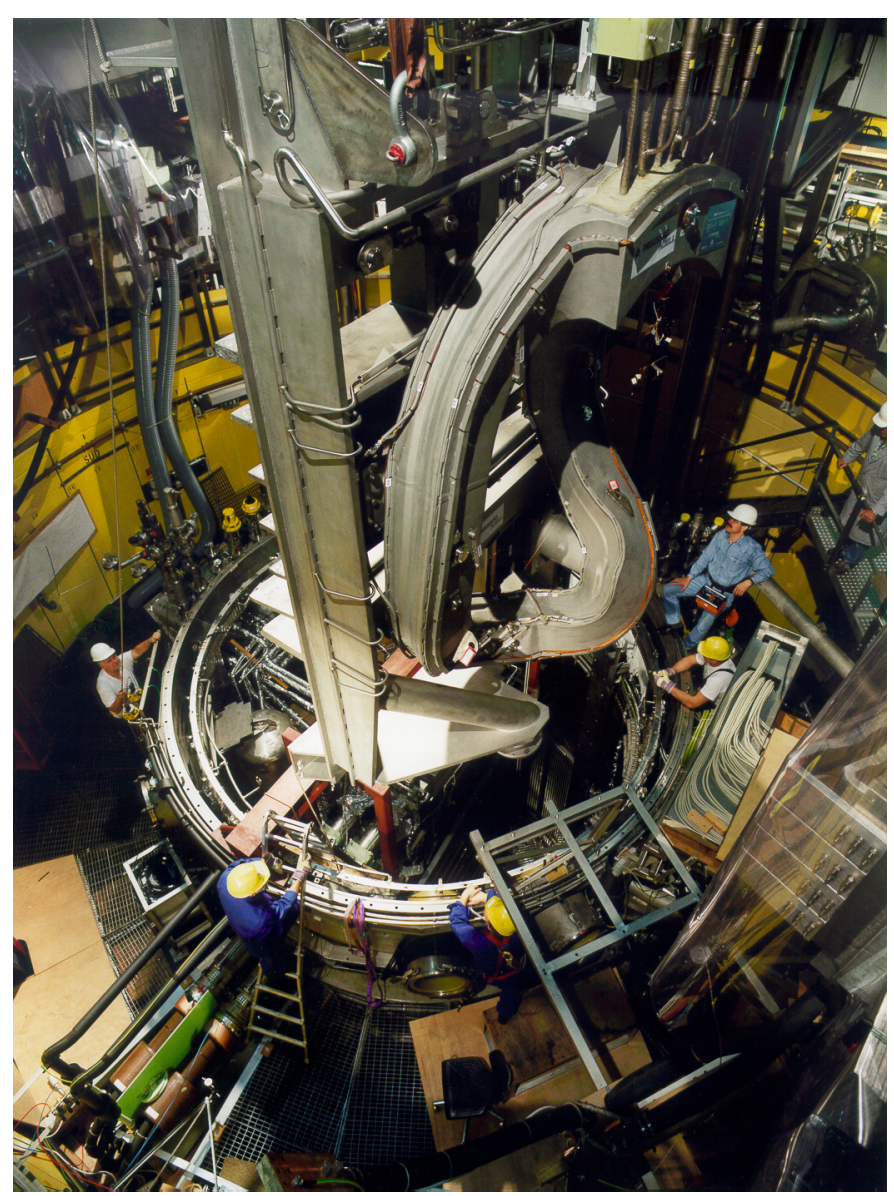

Fig. 2: Prototype coil during the assembly in the TOSKA test facility of FZK (by courtesy of FZK)

The thermal insulation of the superconducting coils is provided by the cryostat. The large temperature differences between the magnet coils and the plasma as well as the arrangement of all components within a limited space are demanding for the design and construction of the cryostat.

A DEMO cryostat, which represents one eighth of the stellarator, was manufactured by Balcke Dürr AG in order to gain experience for the design and assembly of the W7-X cryostat.

The superconducting coils are simulated by dummies. The cooling of the electric connections between the coils will be tested at cryogenic temperatures. The complicated form of the plasma vessel was realised within a given tolerance of $15 \mathrm{~mm}$ using a weld construction with prefabricated steel rings. Due to the small clearance between the plasma vessel, the coils, the coil support structure and the thermal insulation, the assembly of all parts had to be closely interactive. After mounting the coil system and the plasma vessel into the outer vessel the ports which connect the access holes in the plasma vessel with the outer vessel had to be welded. Bake out of the plasma vessel and of the ports to $150^{\circ} \mathrm{C}$ can be done by electric heaters on the outside of the plasma vessel and the ports. To compensate for the thermal 
expansion of the plasma vessel resp. shrinkage of the magnet coils the position of the plasma vessel can be adjusted relative to the magnet system within a range of $2 \mathrm{~cm}$ (Fig.3.) /7/

The DEMO cryostat was mechanically completed in September and is now undergoing a leak test and mechanic and cryogenic function tests.

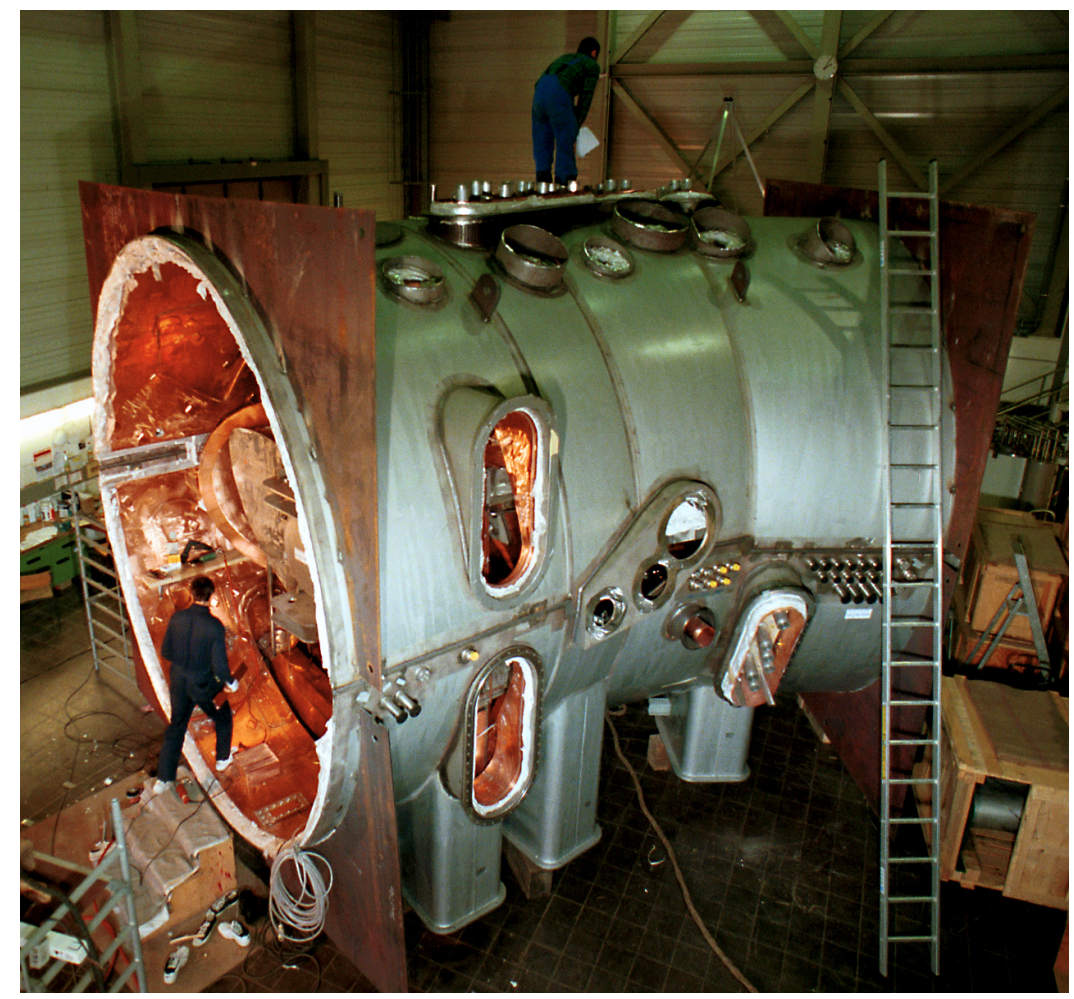

Fig. 3: Assembly of the DEMO cryostat at IPP (by courtesy of Balcke Dürr AG)

Plasma facing components need to be developed for the steady state operation of W7-X. This holds for the target plates of the divertor, the baffle plates and the wall protection. For the target plates carbon tiles brazed onto a water-cooled TZM (Titanium-ZirconiumMolybdenum) base plate were manufactured by Plansee and have been successfully tested under steady state condition and cyclic loads of up to $10 \mathrm{MW} / \mathrm{m}^{2}$ at Forschungszentrum Jülich and the test facilities of CEA in Le Creusot. The cooling channels machined into the TZM base plate are optimised for maximum heat transfer at minimum pressure drop. /8/

The wall of the plasma vessel and the baffles are heated by hot particles and radiation. Plane graphite plates screwed to cooled copper structures are used for the baffles which are loaded up to $0.5 \mathrm{MW} / \mathrm{m}^{2}$. The wall has to be protected against heat loads of up to $0.2 \mathrm{MW} / \mathrm{m}^{2}$.

Therefore large area heat exchange elements, which match the curved surface of the plasma vessel and are coated with carbon or $\mathrm{B}_{4} \mathrm{C}$, are currently being developed by industry.

Another area of development are the microwave sources for heating the electrons in the plasma. Such devices are not yet industrially available for the power and steady state operation required for W7-X. To heat the W7-X plasma continuously by ten sources with one Megawatt each, existing sources must be modified to increase the outlet power at improved efficiency and to optimise the cooling. By the use of a depressed collector the energy of the accelerated electrons is recovered and the efficiency can be increased to $50 \%$. /9/ Prototypes 
of such gyrotrons are being manufactured by Thomson Tube Electronique and Communications \& Power Industries and will be tested at the end of 1999 resp. mid of 2000.

The microwaves emitted by the gyrotrons are transmitted by mirrors and through diamond windows into the plasma. The design and manufacture of prototypes of water cooled mirrors as well as the design of the complete transmission system is being performed at the Institut für Plasmaforschung in Stuttgart.

\section{Status of the project}

The engineering work concentrates on the detail design and specification of the components and on the study of the machine assembly. Major components have been ordered or are in the process of procurement.

The contract for the fifty non-planar coils has been placed with the consortium Noell/Ansaldo. Five production lines are set up to meet the tight delivery dates required for the timely assembly of the modules. At present manufacturing details of the castings for the coil casings are being finalised.

The planar coils are manufactured by the company Tesla. Due to the plane geometry the coil casings can be assembled from plates which are welded and screwed together.

After manufacture all superconducting coils will be tested at nominal current at the cryogenic facilities of Low Temperature Institute of CEA at Saclay. The existing facilities are presently upgraded and cryostats to hold the magnets are being prepared.

To compensate for the large electromagnetic forces the magnet coils are screwed to a massive central steel structure. Additional vault elements between the coil casings balance the compressive forces during operation. The coils and the support structure have a total mass of approx. $400 \mathrm{t}$ and will be cooled by liquid helium. The central support structure has been specified and tender action has started.

The power supplies for the magnets have to deliver up to $20 \mathrm{kA}$ at a maximum voltage of $30 \mathrm{~V}$. To achieve a reproducible magnetic field the currents must be accurate to within $10^{-4}$. The AC fraction of magnet currents must be suppressed to a level of $10 \mathrm{~mA}$. The energy stored in the magnetic field of the coil system of W7-X amounts to $600 \mathrm{MJ}$. To protect the coils against damage a very reliable power supply and protection system is specified. In case of a break in the power supply or a quench the coils are disconnected from the power supply and short-circuited through power resistors where the magnetic energy is converted to heat and removed by air cooling. The procurement of the power supply together with the protection system has been initiated. /10/

The design of the cryostat has to consider several requirements: The plasma vessel has to keep a minimum distance to the magnets to allow for thermal insulation and differential contraction. On the other hand sufficient space has to be provided for the wall protection, the target plates and the 300 ports. Meanwhile the outer vessel and the ports of the cryostat are specified and the shape of the plasma vessel is being finalised. 
The schedule of the project is determined by the construction of the superconducting coils. Delivery of the non-planar coils will start at the end of 2001 in a sequence of approx. 2 coils per month. Assembly will start with half modules using five non-planar and two planar coils. The half modules are joined to modules which are tested and cleaned before the plasma facing components are mounted. The modules are brought to their final position in the torus hall where they are connected to the supply lines. By spring 2006 assembly shall be completed and $6 \mathrm{MW}$ of ECRH and $5 \mathrm{MW}$ of NBI will be available. Commissioning and the scientific operation will start with the cool-down and the mapping of the magnetic surfaces.

A quality management system which is organised according to the standards of ISO 9000 takes care that all steps of design and construction are documented and appropriate quality tests are planned. A comprehensive quality assurance shall make sure that the quality of the machine and the scientific objectives of $\mathrm{W} 7-\mathrm{X}$ are met.

\section{References}

/1/ J. Nührenberg et al.: Overview on Wendelstein 7-X Theory. Trans. Fusion Technology 27, 71-78 (1995)

/2/ G. Grieger et al.: Physics Optimization Stellarators. Physics of Fluids B4, 2081-2091 (1992)

/3/ H. Wobig: The Theoretical Basis of a Drift-Optimized Stellarator Reactor. Plasma Physics and Controlled Fusion 35, 903-917 (1993)

/4/ G. Grieger, J. Nührenberg, H. Renner, J. Sapper, H. Wobig: HELIAS Stellarator Reactor Studies and Related European Technology Studies. Fusion Engineering and Design 25, 73-84 (1994)

15/ J. Kisslinger, C.D. Beidler, E. Harmeyer, F. Herrnegger, H. Wobig, W. Maurer: Coil System of a Helias Reactor. $17^{\text {th }}$ IAEA Fusion Energy Conf., Yokohama 1998

/6/ H. Kronhardt, O. Dormicchi, J. Sapper: Design and Manufacturing of a WENDELSTEIN 7-X DEMO Coil. In: Proc. $20^{\text {th }}$ Symp. on Fusion Technnology, Marseille 1998, 735-738

/7/ A. Brenner, H.G. Grobelny, M. Podhorsky, F. Schauer, B.Sombach: Design and Manufacture of the Demonstration Cryostat for the Fusion Experiment Wendelstein 7-X. In: Proc. $20^{\text {th }}$ Symp. on Fusion Technnology, Marseille 1998, 1725-1728

18/ H. Greuner, A. Hermann, H. Renner, P. Chappuis, R. Mitteau: Development of Divertor Targets for WENDELSTEIN 7-X. In: Proc. $20^{\text {th }}$ Symp. on Fusion Technnology, Marseille 1998, 249-252

19/ M. Romé, V. Erckmann, U. Gasparino, N. Karulin: Electron Cyclotron Resonance Heating and Current Drive in the W7-X Stellarator. Plasma Physics and Controlled Fusion 40, 511-530 (1998)

/10/ A. Nitsche, J. Sapper: Power Supply and Quench Protection for the WENDELSTEIN 7X Magnet. In: Proc. $20^{\text {th }}$ Symp. on Fusion Technnology, Marseille 1998, 755-762 